\title{
The Study of Physical Properties and Analysis of Welding Parameters of A Butt Joint of C45 Steel in MIG Welding
}

\author{
${ }^{1}$ Mr. Amit Dhar, ${ }^{2}$ Mr. Aditya Sadhukhan \\ ${ }^{1}$ Assistant Professor, M.I.E.T., Bandel, India, mtdhar96@gmail.com \\ ${ }^{2}$ UG Student, M.I.E.T., Bandel, India, adityasadhukhan0@gmail.com
}

Abstract: This project shows the effect of welding variables on the mechanical properties of $\mathbf{C 4 5}$ steel. This medium carbon steel plate of $10 \mathrm{~mm}$ thickness welded using the Metal Inert Gas Welding. Welding current, voltage, root gap are the welding parameters. The hardness and tensile strength of weld specimen are investigated in this study. The results showed that the selected welding parameters had significant effects on the mechanical properties of the welded samples. The welded samples were cut and machined to standard configurations (dog bone sample) for tensile and hardness tests. The selected three input parameters were varied at three levels on the analogy; nine experiments were performed based on L9 array of Taguchi's methodology, which consist three input parameters. Analysis of variance (ANOVA) was employed to find the levels of significance of input parameters. Root gap has greatest effect on tensile strength followed by welding current and voltage. Voltage has the greatest effect on hardness followed by root gap and welding current. The relative studies of machining performances on the basis of metallurgical properties are properties are prepared by the help of statistical tools, i.e. L9 Orthogonal Array, ANOVA etc.

Keywords: ANOVA, GMAW, Root Gap, Taguchi, Welding Current, Welding Voltage.

\section{INTRODUCTION}

Steel is an important material in engineering industry for its mechanical properties such as high strength, rigidity, good corrosion resistance and wear resistance. Welding is a permanent joining process used to join different materials. This joining is obtained by the application of heat. Due to the application of heat some metallurgical or structural change occurs inside the material. These structural or metallurgical changes depend on the welding parameters such as welding current, voltage, root gap etc. Welding involves a wide range of variables such as time, temperature, electrode, pulse frequency, power input and welding speed which influence the mechanical properties of the weldment. Proper selection of welding parameters, proper combination of welding parameters with specific range provides a good weld quality. So experimental research is required to generate data for welding which can give desired properties. The effect of welding parameters on the mechanical properties of $\mathrm{C} 45$ steel welded joints was studied in this research. The experiment was carried out to know that, how these welding parameters affect the mechanical properties of the welded sample.

\section{LITERATURE REVIEW}

In the present study we can consider welding voltage, welding current, electrode diameter, thickness of specimen/plate, no of passes, types of joints as input parameter to test and thereby metals property like microstructure, weld quality through Tensile test, Brinell/Rockwell Hardness test, Charpy Impact test,
Compression test, Bending test, Torsion test\& Shear test. The study can be extended by considering other parameters like arc time, weld angle, selecting Filler material \& welding types as a future scope over HAZ \& Metallographic examination.

[1] Danial T, Timotius P, Mazlar R

Department of Mechanical Engineering, Auckland University of Technology, New Zealand

This paper discussed the effect of welding variables on the mechanical properties of welded $2 \mathrm{~mm}$ thick low copper and mild steel plate, welded using the Gas Tungsten arc welding (TIG) method. Welding current, arc voltage, welding speed and electrode diameter were the investigated welding parameters.

[2] R. Sudarshan, Dr. M. Devaiah

Geethajali College of Engineering and Technology, Cheeryal(V), Keesara (M), Medchal, Telangana, India

The main objective of this paper is to predict and optimize MIG welding of some economically important similar materials and dissimiliar material in the industry through applying a statistical approach to SPSS software, develop mathematical models and optimize the welding operation. This was achieved by controlling selected welding parameters; V-butt angles welding current and welding voltage position, to relate the ultimate tensile strength to the selected input welding parameters. The material studied in this work are mild steel IS2062.

[3] Praveen Kumar Yadav, Md Abbas, Shishirpatel 
Department of Mechanical Engineering, IEC College of Engineering and Technology, Greater Noida.

In this project, it was observed that for increase in voltage there is increase in penetration and there is slight increase in HAZ, hardness with respect to increase in current.

[4] Rakesh Kumar, Satish Kumar

M.Tech scholar, Department of Mechanical Engineering, HCTM Technical Campus, Kaithal, Haryana, IndiaAssistant Professor, Department of Mechanical Engineering, HCTM Technical Campus, Kaithal, Haryana, India.

The aim of the present study is to show the influence of different parameters such as welding current, arc voltage and root gap on the mechanical properties during the Metal Inert Gas Welding (MIG) of mild steel 1018 grade. The microstructure, hardness and tensile strength of the weld specimen are investigated in this study. The selected three input parameters are varied at three levels. On the analogy, nine experiments were performed based on L9 orthogonal array of Taguchi's methodology, which consist three input parameters. Analysis of variance (ANOVA) was employed to find the levels of significance of input parameter.

\section{MATERIAL SELECTION}

\section{C45 Grade Steel:}

C45 grade steel is medium carbon steel offering moderate tensile strengths. $\mathrm{C} 45$ steel is hardened by flame hardening or induction hardening process instead of using quenching and tempering process. Because of a limited section can be hardened by quenching and tempering process. It can be hardened up to HRC 55.The Machinability of C45 steel is quite similar to the mild steel.

\section{Material:}

The material used for metal inert gas welding (MIG) is C45 grade steel. The entire specimen was machined into the dimension of $300 \mathrm{~mm}$ long $\times 50 \mathrm{~mm} \times 10 \mathrm{~mm}$ thick. The composition of the specimen is shown in Table 1. C45 grade steel is a medium carbon steel which offers moderate tensile strength. This grade is most commonly supplied in normalized conditions. Machinability is similar to that of mild steel, however higher carbon content compare to mild steel the weld ability of C45 grade steel is reduced.

\section{Chemical Composition of $\mathbf{C 4 5}$ Grade Steel:}

\begin{tabular}{|c|c|c|c|c|}
\hline $\mathrm{C}$ & $\mathrm{Mn}$ & $\mathrm{Si}$ & $\mathrm{S}$ & $\mathrm{P}$ \\
\hline $0.45 \%$ & $0.76 \%$ & $0.23 \%$ & $0.026 \%$ & $0.034 \%$ \\
\hline
\end{tabular}

Table-1: Chemical Composition of C45 Steel

\section{DESIGN OF EXPERIMENT}

\section{L9 Orthogonal Array:}

In the present work the L9 orthogonal array is used with three factors and three levels for each factor to design the experiment with 9 combination sets.

\begin{tabular}{|c|c|c|c|}
\hline No. of Observation & $\underline{\mathbf{A}}$ & $\underline{\mathbf{B}}$ & $\underline{\mathbf{C}}$ \\
\hline 1. & 1 & 1 & 1 \\
\hline 2. & 1 & 2 & 2 \\
\hline 3. & 1 & 3 & 3 \\
\hline 4. & 2 & 1 & 2 \\
\hline 5. & 2 & 2 & 3 \\
\hline 6. & 2 & 3 & 1 \\
\hline 7. & 3 & 1 & 3 \\
\hline 8. & 3 & 2 & 1 \\
\hline 9. & 3 & 3 & 2 \\
\hline
\end{tabular}

The four input parameters chosen for the experiment : Table 3- Input Parameters

\begin{tabular}{|c|c|c|c|}
\hline Level & $\begin{array}{l}\text { Welding } \\
\text { Voltage (V) }\end{array}$ & $\begin{array}{l}\text { Welding } \\
\text { Current (A) }\end{array}$ & $\begin{array}{l}\text { Root Gap } \\
(\mathbf{m m})\end{array}$ \\
\hline 1 & 21 & 150 & 2 \\
\hline 2 & 25 & 162 & 3 \\
\hline 3 & 30 & 172 & 4 \\
\hline
\end{tabular}

\section{EXPERIMENTAL METHODS FOR MECHANICAL TESTING}

\section{Sample Preparation of Test Specimen:}

Machining the $\mathrm{C} 45$ steel plate and produce the double side $\mathrm{V}$ on the plate. The dimension of the plate is 300,50 .
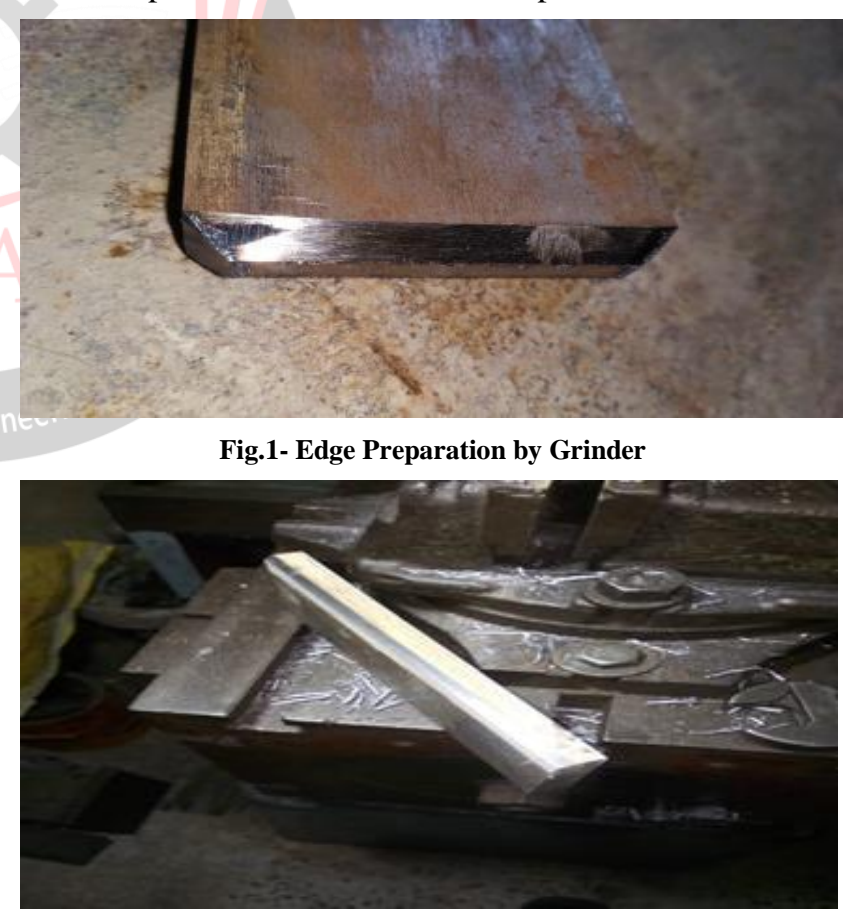

Fig.2- Machined by Shaper

\section{Welding of Test Specimen:}

In this process the welding gun or torch is connected to the positive terminal and the earthing is connected to the negative terminal. Remote control socket provided for welding at a long distance from the welding power source. A display is also attached to the welding machine which shows the voltage and current. The voltage and current is adjusted by the regulating knob or regulator. The heat is 
provided by an electric arc to melt the metal. A consumable metallic electrode is used in the form of wire. The electrode is driven through the drive wheels. This metallic electrode also acts as the filler material. This process is carried out by D.C. with reverse polarity. The weld zone is shielded from the atmosphere by an inert gas i.e., carbon-di-oxide $\left(\mathrm{CO}_{2}\right)$. The gun's gas nozzle is periodically cleaned to remove spatter buildup. The wire is fed with a constant speed to obtain a high deposition rate.

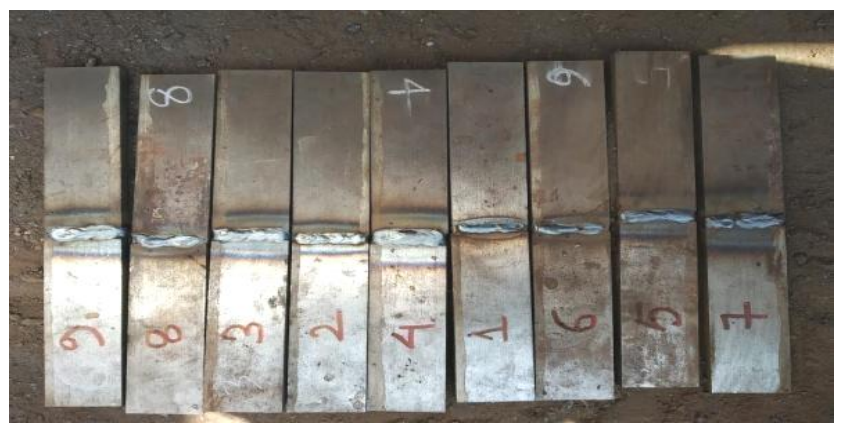

Fig.3- Single V Butt Joint

\section{Hardness Test of Test Specimen:}

The indenter is pressed with a load to the penetration depth in the weld zone of the test specimen. This load is taken as the reference level. After that an additional load is applied for a specific period. This specific period is termed as dwell period. Then the indenter penetrates into the specimen to a maximum indentation depth. The reference load plus the additional load gives the total test load. It is also referred to as total force or total load. After the dwell period, the additional test force is removed. Now the Rockwell hardness (HR) can be calculated, using the indentation depth and a standard formula according to the Rockwell scale.

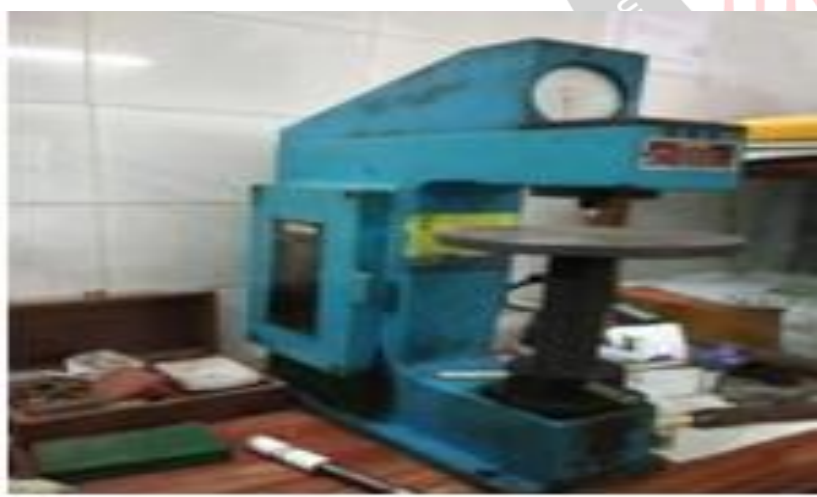

Fig.4-Rockwell Hardness Testing Machine

Tensile Test of Weld Zone of Test Specimen:

The pointer is set at zero by adjusting the setting knob. The dial gauge is fixed and the specimen for measuring elongation of small amounts. The length and width of the test specimen are measured by vernier caliper to determine the mean value and the gauge length. Then the gauge length is marked on the test specimen. The specimen is gripped between upper and lower jaws of the machine. The tensile load is applied on the test specimen gradually and the elongation is noted until the specimen breaks.

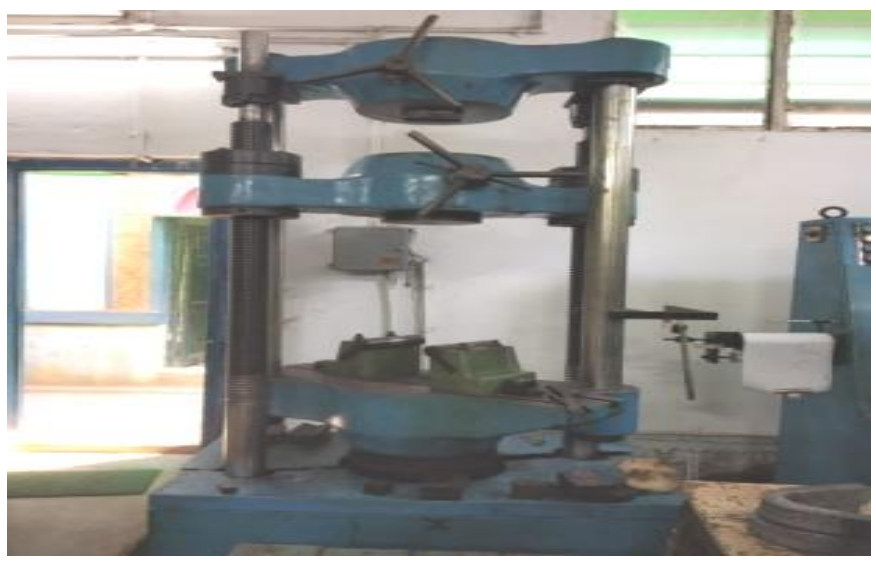

Fig.5-Universal Testing Machine

\section{EXPERIMENTATION AND DATA ACQUISITION}

\section{Data of Hardness Test:}

\begin{tabular}{|c|c|}
\hline Sl. Number & $\begin{array}{c}\text { Result of Experiment for } \\
\text { Hardness Test (HRBW) }\end{array}$ \\
\hline 1. Test Specimen & 98.7 \\
\hline 2. Test Specimen & 93.0 \\
\hline 3. Test Specimen & 89.3 \\
\hline 4. Test Specimen & 89.7 \\
\hline 5. Test Specimen & 91.3 \\
\hline 6. Test Specimen & 96.3 \\
\hline 7. Test Specimen & 88.7 \\
\hline 8. Test Specimen & 93.0 \\
\hline 9. Test Specimen & 92.3 \\
\hline
\end{tabular}

Table 4- Hardness Test Result

Data of Tensile Test:

\begin{tabular}{|c|c|}
\hline Sl. Number & $\begin{array}{c}\text { Result of Experiment for } \\
\text { Tensile Test (MPa) }\end{array}$ \\
\hline 1. Test Specimen & 465 \\
\hline 2. Test Specimen & 581 \\
\hline 3. Test Specimen & 504 \\
\hline 4. Test Specimen & 547 \\
\hline 5. Test Specimen & 479 \\
\hline 6. Test Specimen & 475 \\
\hline 7. Test Specimen & 472 \\
\hline 8. Test Specimen & 512 \\
\hline 9. Test Specimen & 520 \\
\hline
\end{tabular}

Table 5- Tensile Test Result

\section{Data of Experimental Readings:}

Table 6- Data of Experimental Readings

\begin{tabular}{|c|c|c|c|c|c|}
\hline Sl. No. & $\begin{array}{c}\text { Voltage } \\
(\mathrm{V})\end{array}$ & Current(A) & $\begin{array}{c}\text { Root Gap } \\
(\mathrm{mm})\end{array}$ & $\begin{array}{c}\text { Hardness Test } \\
(\mathrm{HRBW})\end{array}$ & $\begin{array}{c}\text { Tensile Test } \\
(\mathrm{MPa})\end{array}$ \\
\hline 1. & 21 & 150 & 2 & 98.7 & 465 \\
\hline 2. & 21 & 162 & 3 & 93.0 & 581 \\
\hline 3. & 21 & 172 & 4 & 89.3 & 504 \\
\hline 4. & 25 & 150 & 3 & 89.7 & 547 \\
\hline 5. & 25 & 162 & 4 & 91.3 & 479 \\
\hline 6. & 25 & 172 & 2 & 96.3 & 475 \\
\hline 7. & 30 & 150 & 4 & 88.7 & 472 \\
\hline 8. & 30 & 162 & 2 & 93.0 & 512 \\
\hline 9. & 30 & 172 & 3 & 92.3 & 520 \\
\hline
\end{tabular}




\section{DISCUSSION AND ANALYSIS}

Testing Performance on C45 Steel:

The growing demand of welding processes has explored different combinations of work interface with a large variance in different welding parameters like hardness and tensile strength. The common objective of welding performance is to obtain the maximum tensile strength and hardness on the weld zone by varying the welding input parameters such as current, voltage and root gap. The welding performance test for tensile testing process in Universal Testing Machine for the welding behavior of C45 steel has been analyzed. After finding the results they are further analyzed in MINITAB 18 software for the effects of different parameters and to project Contour Plots and Scatter Plots.

\section{Taguchi Analysis: Tensile Test vs. Voltage, Current \&Root Gap}

Nominal is best $\left\{10 \times \log 10\left(\operatorname{Ybar}^{\wedge} 2 / \mathrm{s}^{\wedge} 2\right)\right\}$

\begin{tabular}{|c|c|c|c|}
\hline Level & Voltage & Current & Root Gap \\
\hline 1 & 516.7 & 494.7 & 484.0 \\
\hline 2 & 500.3 & 524.0 & 549.3 \\
\hline 3 & 501.3 & 499.7 & 485.0 \\
\hline Delta & 16.3 & 29.3 & 65.3 \\
\hline Rank & 3 & 2 & 1 \\
\hline
\end{tabular}

Table 7- Taguchi Analysis: Tensile Test vs. Voltage, Current \& Root Gap

Main Effect Plot for Means Data Means for Tensile Test

Here different experimental values of voltage, current and root gap are compared with the other experimental values. The effect of experimental values of different factors i.e. voltage, current and root gap on the tensile strength are tested. The following is the main effects plots of these three factors. The reference line (horizontal dashed line in between the value of 500 and 510 i.e. black in color) represents the overall mean. When the stepper line or slope (continuous line which joined the values of different factors i.e. blue in color) is horizontal i.e. parallel to the $\mathrm{x}$ axis, then there is no main effect. Each level of factor affects the response in the same way, and the response mean is same across all factor levels. When the line is not horizontal, then there is a main effect. Different levels of the factor affect the response differently. The stepper the slope of the line, the greater the magnitude of the main effect.

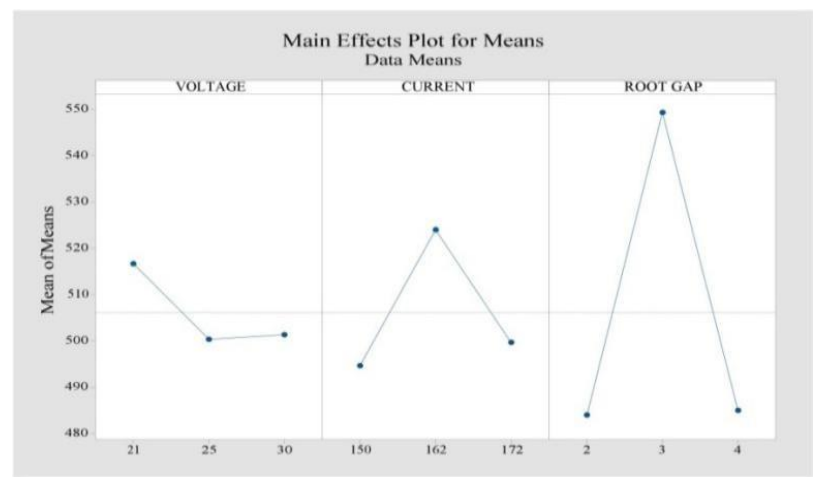

Fig.6- Taguchi Analysis: Tensile Test vs. Voltage, Current \& Root Gap

For example, the effect of $21 \mathrm{~V}$ on the tensile strength is compared with the effect of other two voltages i.e. $25 \mathrm{~V}$ and $30 \mathrm{~V}$ on the tensile strength. Voltage seems to affect the tensile strength because the line is not horizontal. $21 \mathrm{~V}$ has a higher tensile strength mean than the other two voltages i.e. $25 \mathrm{~V}$ and $30 \mathrm{~V}$.

The current also affects the tensile strength. The effect of $162 \mathrm{~A}$ on the tensile strength is compared with the effect of other two current rating i.e. $150 \mathrm{~A}$ and $172 \mathrm{~A}$ on the tensile strength. Moderate level current rating i.e. 162A has a higher tensile strength mean than the other current rating i.e. $150 \mathrm{~A}$ and $172 \mathrm{~A}$.

Similarly the effect of root gap $3 \mathrm{~mm}$ on the tensile strength is compared with the effect of other two root gap $2 \mathrm{~mm}$ and $4 \mathrm{~mm}$ on the tensile strength. It shows that root gap of $3 \mathrm{~mm}$ has a higher tensile strength mean than the other two root gap i.e. $2 \mathrm{~mm}$ and $4 \mathrm{~mm}$.

Taguchi Analysis: Hardness Test vs. Voltage, Current \& Root Gap

Nominal is best $\left\{10 \times \log 10\left(\operatorname{Ybar}^{\wedge} 2 / \mathrm{s}^{\wedge} 2\right)\right\}$

\begin{tabular}{|c|c|c|c|}
\hline Lerinel & Voltage & Current & Root Gap \\
\hline 1 & 93.67 & 92.37 & 96.00 \\
\hline 2 & 92.43 & 92.43 & 91.67 \\
\hline 3 & 91.33 & 92.63 & 89.77 \\
\hline Delta & 2.33 & 0.27 & 6.23 \\
\hline Rank & 2 & 3 & 1 \\
\hline
\end{tabular}

Table 8- Taguchi Analysis: Hardness Test vs. Voltage, Current \& Root Gap

\section{Main Effect Plot for Means Data Means for Hardness Test}

Here different experimental values of voltage, current and root gap are compared with the other experimental values. The effect of experimental values of different factors i.e. voltage, current and root gap on the hardness are tested. The following is the main effects plots of these three factors. The reference line (horizontal dashed line in between the value of 500 and 510 i.e. black in color) represents the overall mean. When the stepper line or slope (continuous line which joined the values of different factors i.e. blue in color) is horizontal i.e. parallel to the $\mathrm{x}$ axis, then there is no main effect. Each level of factor 
affects the response in the same way, and the response mean is same across all factor levels. When the line is not horizontal, then there is a main effect. Different levels of the factor affect the response differently. The stepper the slope of the line, the greater the magnitude of the main effect.

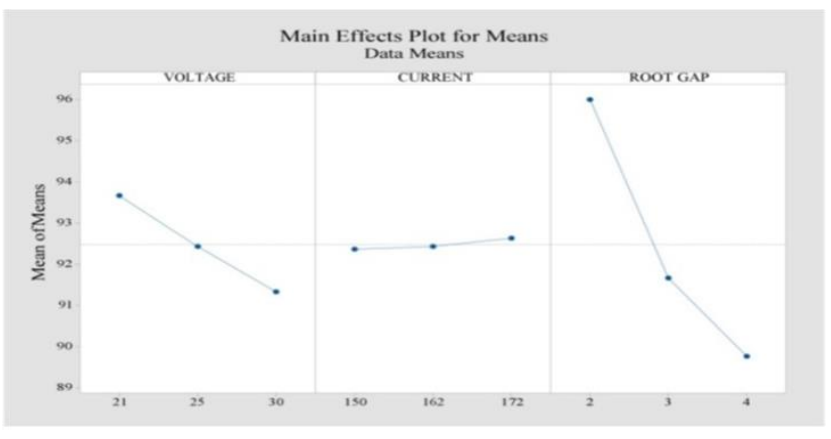

Fig.7-Taguchi Analysis: Hardness Test vs. Voltage, Current \& Root Gap

For example, the effect of $21 \mathrm{~V}$ on the hardness is compared with the effect of other two voltages i.e. $25 \mathrm{~V}$ and $30 \mathrm{~V}$ on the hardness. Voltage seems to affect the hardness because the line is not horizontal. $21 \mathrm{~V}$ has a higher hardness mean than the other two voltages i.e. $25 \mathrm{~V}$ and $30 \mathrm{~V}$.

The current also affects the hardness. The effect of 172A on the hardness is compared with the effect of other two current rating i.e. $150 \mathrm{~A}$ and $162 \mathrm{~A}$ on the hardness. Current rating i.e. $172 \mathrm{~A}$ has a higher hardness mean than the other current rating i.e. $150 \mathrm{~A}$ and $162 \mathrm{~A}$.

Similarly the effect of root gap $2 \mathrm{~mm}$ on the hardness is compared with the effect of other two root gap $3 \mathrm{~mm}$ and $4 \mathrm{~mm}$ on the hardness. It shows that root gap of $2 \mathrm{~mm}$ has a hardness mean than the other two root gap i.e. $3 \mathrm{~mm}$ and $4 \mathrm{~mm}$.

\section{Contour Plot of Tensile Test vs. Current, Voltage}

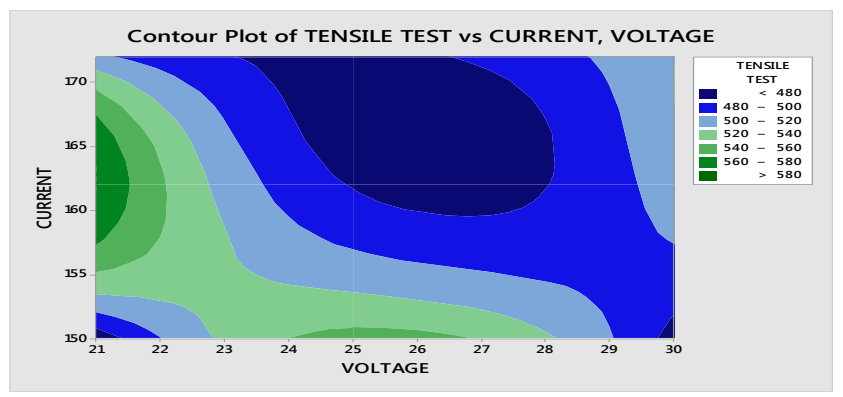

Fig.8- Contour Plot of Tensile Test vs. Current \& Voltage

From the above mentioned figure we can conclude that the combination of medium current (around 160A) with low voltage $(21 \mathrm{~V})$ offers best tensile strength.

\section{Contour Plot of Tensile Test vs. Current, Root Gap}

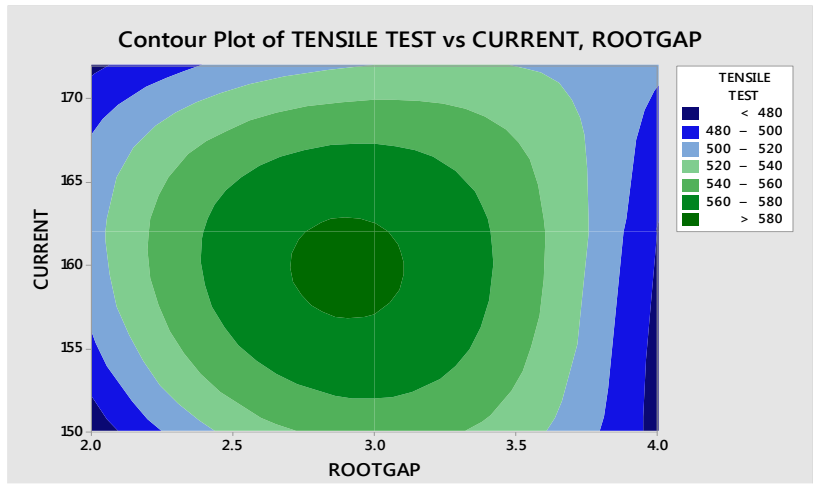

Fig.9- Contour Plot of Tensile Test vs. Current \& Root Gap

From the above mentioned figure we can conclude that the combination of medium current (around 160A) with medium root gap (around $3 \mathrm{~mm}$ ) offers best tensile strength.

\section{Contour Plot of Tensile Test vs. Voltage, Root Gap}

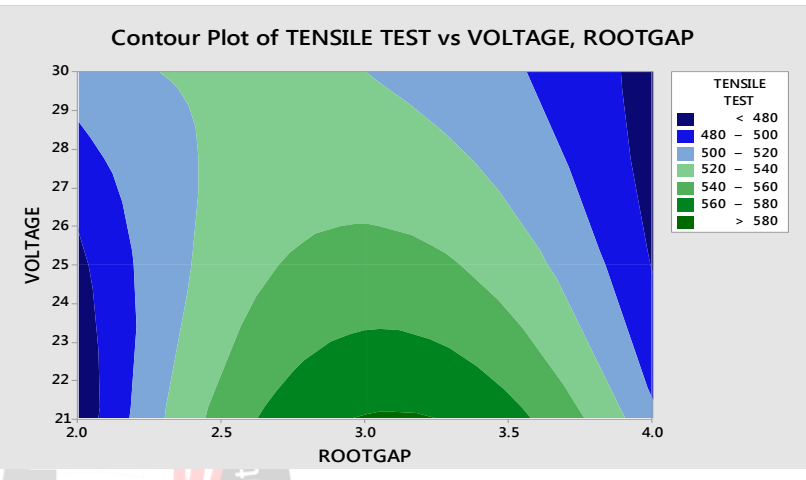

Fig.10- Contour Plot of Tensile Test vs. Voltage \& Root Gap

From the above mentioned figure we can conclude that the combination of low voltage $(21 \mathrm{~V})$ with medium root gap (around $3 \mathrm{~mm}$ ) offers best tensile strength.

Thus, low voltage with medium current and root gap results increasing the tensile strength. Also it shows that root gap plays the most important role for tensile strength.

\section{Contour Plots of Hardness Test vs. Current, Voltage}

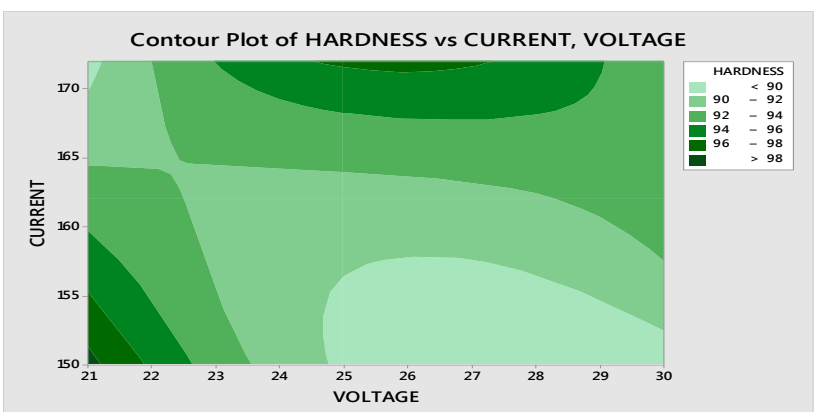

Fig.11- Contour Plot of Hardness vs. Current \& Voltage

From the above mentioned figure we can conclude that the combination of low current (150A) with low voltage (21V) offers the best hardness.

\section{Contour Plots of Hardness Test vs. Current, Root Gap}




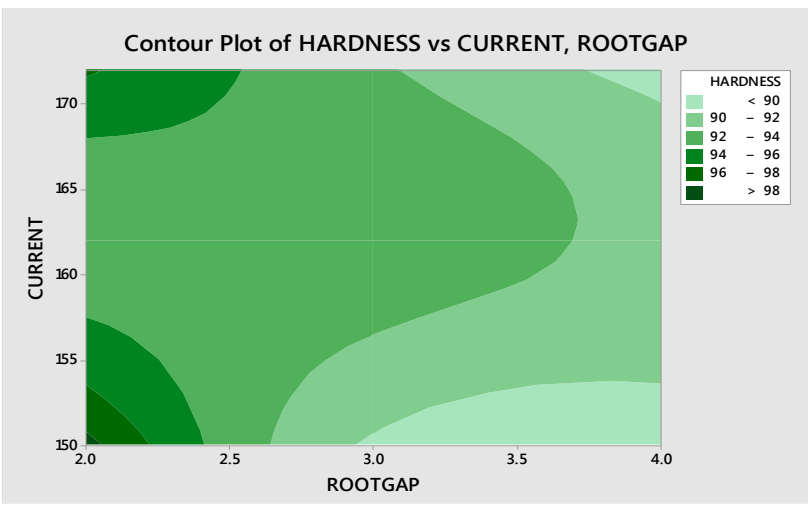

Fig.12- Contour Plot of Hardness vs. Current \& Root Gap

From the above mentioned figure we can conclude that the combination of low current (150A) with low root gap $(2 \mathrm{~mm})$ offers the best hardness.

\section{Contour Plots of Hardness Test vs. Voltage, Root Gap}

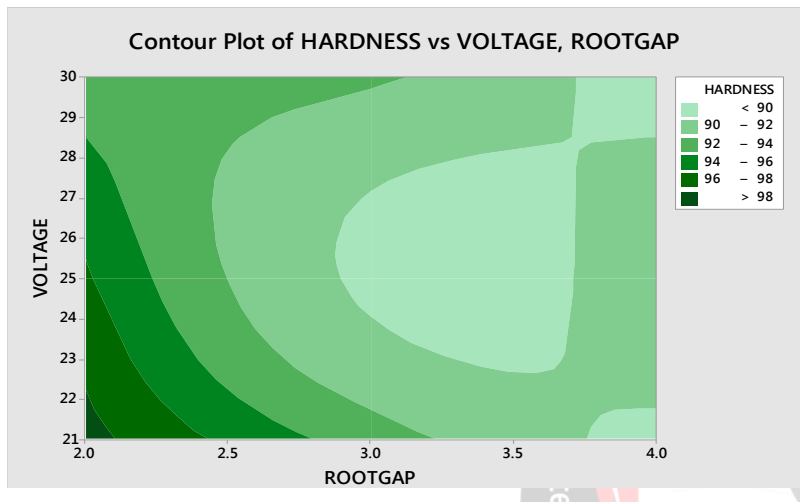

Fig.13- Contour Plot of Hardness vs. Voltage \& Root Gap

From the above mentioned figure we can conclude that the combination of low voltage $(21 \mathrm{~V})$ with low root gap ( $2 \mathrm{~mm})$ offers the best hardness.

Thus, decreasing the current, voltage and root gap results increasing the hardness. Also it shows that root gap plays the most important role for hardness.

General Linear Model: Hardness Test (HRBW) vs. Voltage, Current, Root Gap

Method

Factor Coding $(-1,0,+1)$

\section{Factor Information}

\begin{tabular}{|c|c|c|c|}
\hline Factor & Type & Levels & Values \\
\hline Voltage & Fixed & 3 & $21,25,30$ \\
\hline Current & Fixed & 3 & $150,162,172$ \\
\hline Root Gap & Fixed & 3 & $2,3,4$ \\
\hline
\end{tabular}

Table 9-Facror Information: Hardness Test vs. Voltage, Current, Root Gap

Analysis of Variance

\begin{tabular}{|c|c|c|c|c|c|}
\hline Source & DF & Adj SS & Adj MS & F-Value & $\begin{array}{c}\text { P- } \\
\text { Value }\end{array}$ \\
\hline Voltage & 2 & 8.1756 & 4.0878 & 0.46 & 0.686 \\
\hline Current & 2 & 0.1156 & 0.0578 & 0.01 & 0.994 \\
\hline
\end{tabular}

\begin{tabular}{|c|c|c|c|c|c|}
\hline $\begin{array}{c}\text { Root } \\
\text { Gap }\end{array}$ & 2 & 61.2422 & 30.6211 & 3.43 & 0.226 \\
\hline Error & 2 & 17.8422 & 8.9211 & - & - \\
\hline Total & 8 & 87.3756 & - & - & - \\
\hline
\end{tabular}

Table 10-Analysis of Variance: Hardness Test vs. Voltage, Current, Root Gap

Regression Equation

Hardness: 106.4 - 0.258 Voltage + 0.0119Current - 3.117

Root Gap

General Linear Model: Tensile Test (MPa) vs. Voltage, Current, Root Gap

Method

Factor Coding $(-1,0,+1)$

\section{Factor Information}

\begin{tabular}{|c|c|c|c|}
\hline Factor & Type & Levels & Values \\
\hline Voltage & Fixed & 3 & $21,25,30$ \\
\hline Current & Fixed & 3 & $150,162,172$ \\
\hline Root Gap & Fixed & 3 & $2,3,4$ \\
\hline
\end{tabular}

Table 11-Facror Information: Tensile Test vs. Voltage, Current, Root Gap

Analysis of Variance

\begin{tabular}{|c|c|c|c|c|c|}
\hline Source & DF & Adj SS & Adj MS & F-Value & P-Value \\
\hline Voltage & 2 & 502.9 & 251.4 & 0.30 & 0.770 \\
\hline Current & 2 & 1477.6 & 738.8 & 0.88 & 0.532 \\
\hline Root Gap & 2 & 8408.2 & 4204.1 & 5.00 & 0.167 \\
\hline Error & 2 & 1680.2 & 840.1 & - & - \\
\hline Total & 8 & 12068.9 & - & - & - \\
\hline
\end{tabular}

Table 12-Analysis of Variance: Tensile Test vs. Voltage, Current, Root Gap

Regression Equation

Tensile Strength: 497 - 1.63 Voltage + 0.30 Current + 0.5 Root Gap

\section{Computation of Sum of Squares and Percentage Contribution}

Calculation of sum of square for Tensile Test

$$
\begin{aligned}
\mu & =(465+581+504+547+479+475+472+512+520) / 9 \\
& =506.11
\end{aligned}
$$

Adj. SS $=(506-465)^{2}+(506-581)^{2}+(506-504)^{2}+(506-$ $547)^{2}+(506-479)^{2}+(506-475)^{2}+(506-472)^{2}+(506-512)^{2}+$ $(506-520)^{2}$

Or, Adj.SS = 12069

Percentage of Contribution:

Voltage- $(251.4 / 12069) * 100=2.083 \%$

Current- $(738.8 / 12069) * 100=6.121 \%$

Root Gap- $(4204.1 / 12069) * 100=34.833 \%$

Calculation of sum of square for Hardness Test 
$\mu=(98.7+93+89.3+89.7+91.3+96.3+88.7+93+94.3) / 9$

$$
=92.7
$$

Adj. SS $=(92.7-98.7)^{2}+(92.7-93)^{2}+(92.7-89.3)^{2}+(92.7-$ $89.7)^{2}+(92.7-91.3)^{2}+(92.7-96.3)^{2}+(92.7-88.7)^{2}+(92.7-$ $93)^{2}+(92.7-94.3)^{2}$

Or, Adj.SS $=90.22$

Percentage of Contribution:

Voltage- $(8.1756 / 90.22) * 100=9.061 \%$

Current- $(0.1156 / 90.22) * 100=0.128 \%$

Root Gap-(61.242/90.22)*100=67.880\%

\begin{tabular}{|c|c|c|c|}
\hline Aspect & Voltage & Current & Root Gap \\
\hline Hardness & 9.061 & 0.128 & 67.880 \\
\hline Rank & 2 & 3 & 1 \\
\hline Tensile Strength & 2.083 & 6.121 & 34.833 \\
\hline Rank & 3 & 2 & 1 \\
\hline
\end{tabular}

Table 13- Percentage Contribution of Voltage, Current \& Root Gap on Hardness \& Tensile Strength

From the calculation of "Percentage Contribution" we can conclude that, the root gap ranks $1^{\text {st }}$ and highest significant parameter in variance of both hardness \& tensile strength. The contribution of current is least on hardness whereas for tensile strength voltage plays the least significant parameter.

\section{Conclusion}

Hence it is observed that the welding parameters are the most influencing factors for the output. In this present study root gap plays the major role for both tensile test and hardness. We can conclude that medium level current rating of $160 \mathrm{~A}$ with low level voltage $21 \mathrm{~V}$ and medium level root gap $3 \mathrm{~mm}$ offers best tensile strength. Finally it can be considered that for achieving best tensile strength; root gap has to keep in the moderate level \& taking voltage at lower level \& current at medium level. On the other hand; low level current of 150A with low level voltage of $21 \mathrm{~V}$ and low level root gap of $2 \mathrm{~mm}$ offers high hardness. To obtain the best hardness, we have to keep the root gap, voltage and current at lower level. Welding through these suitable adjustments of various parameters for C45 steel has much effect on final output. It can be conclude that the above phenomenon are able to provide the most efficient result for butt joint of $\mathrm{C} 45$ steel in MIG welding (GMAW). Also in the present study Root gap plays the major role for achieving higher tensile strength and hardness.

\section{REFRERENCE}

[1] Danial T, Timotius P, MazlarR , Gas Tungsten Arc Welding of Copper and Mild steel, Department of Mechanical Engineering, Auckland University of Technology, New Zealand, 27/04/2016.

[2] R. Sudarshan, Dr. M. Devaiah, Effect of Process Parameters in MIG Welding on Mild Steel IS 2062, Geethajali College of Engineering and Technology, Cheeryal(V), Keesara (M), Medchal, Telangana,
India(Corresponding Author),International Journal of Applied Engineering Research ISSN 0973-4562 Volume 13,

Number 4 (2018) pp. 2046-2054

[3] Praveen Kumar Yadav, Md Abbas, Shishirpatel, Analysis of Heat Effected Zone on Mild Steel Specimen developed due to MIG Welding, Department of Mechanical Engineering, IEC College of Engineering and Technology, Greater Noida,Vol. 3, No. 3, July, 2014 (c) 2014.

[4] Rakesh Kumar, Satish Kumar, M.Tech scholar, Department of Mechanical Engineering, HCTM Technical Campus, Kaithal, Haryana, India Assistant Professor, Department of Mechanical Engineering, HCTM Technical Campus, Kaithal, Haryana, India Published - May 8, 2018

[5] Douglas C. Montgomery, "Design and analysis of experiments", John Wiley \& Sons, Inc., ISBN978-1118-14692-7

[6] Dr. O.P.Khanna, A Textbook of Welding Technology. Haryana, Dhanpat Rai Publications (P) LTD. 22 Ansari Road, Daryaganj, New Delhi-110002, Reprint 2017 ISBN: 978-93-83182-55-8

[7] Amitabha Ghosh \& Asok Kumar Mallik, Manufacturing Science. East-West Press Private Limited, ISBN: 978-81-7671-063-3; Reprint 2019

[8] Dr. K.S.Yadav, Advanced Welding Technology. S.Chand Publications, ISBN:9788189401542, Reprint 2017

[9] Rao P.N., Manufacturing Technology : Volume 1 - Foundry, Forming and Welding - Volume 1, McGraw Hill, ISBN: 9781259062575, 1259062570

[10] M. Young, The Technical Writers Handbook. Mill Valley, CA: University Science, 1989. 